\title{
A produçáo de acesso da populaçáo idosa ao território da cultura: uma experiência de Terapia Ocupacional num museu de arte
}

\author{
Ana Tereza Costa Galvanese ${ }^{a}$, Sylvio Coutinho ${ }^{\mathrm{b}}$, Erika Alvarez Inforsato ${ }^{\mathrm{c}}$, \\ Elizabeth Maria Freire de Araújo Lima ${ }^{d}$
}

\begin{abstract}
aDepartamento de Medicina Preventiva, Faculdade de Medicina da Universidade de São Paulo - FMUSP, São Paulo, SP, Brasil

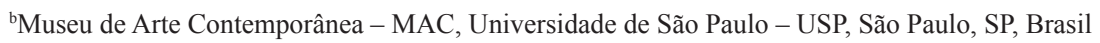

' Laboratório de Estudos e Pesquisa Arte, Corpo e Terapia Ocupacional,

Curso de Terapia Ocupacional da Faculdade de Medicina da Universidade de São Paulo - FMUSP, Faculdade de Educação, Universidade de São Paulo - USP,. São Paulo, SP, Brasil

${ }^{\mathrm{d} C}$ Curso de Terapia Ocupacional, Laboratório de Estudos e Pesquisa Arte, Corpo e Terapia Ocupacional, Faculdade de Medicina da Universidade de São Paulo - FMUSP,
\end{abstract}

São Paulo, SP, Brasil

\begin{abstract}
Resumo: De 1996 a 2009, o Laboratório de Estudos e Pesquisas Arte, Corpo e Terapia Ocupacional estabeleceu uma cooperação com o Museu de Arte Contemporânea da USP (MAC-USP), atuando em parceria no Lazer com Arte para a Terceira Idade (LAPTI), programa da Divisão Técnico-Científica de Educação e Arte do Museu de Arte Contemporânea - MAC-USP, que oferece à população idosa uma iniciação na práxis artística contemporânea. O presente artigo apresenta a experiência do trabalho interdisciplinar desenvolvido no LAPTI no ano de 2006. O método adotado no programa tem como referência a Abordagem Triangular de Ensino da Arte. Assim, a apreciação das obras do acervo e a contextualização das poéticas visuais de artistas selecionados formaram a base a partir da qual os participantes desenvolveram suas próprias poéticas. Em momento preparatório para o trabalho em ateliê, foram desenvolvidas dinâmicas de grupo, nas quais o terapeuta ocupacional e o estagiário coordenavam atividades de percepção corporal, rodas de conversa e acompanhamento dos participantes em suas demandas ligadas aos desafios da criação e do acesso aos territórios socioculturais. A relevância do processo vivido evidenciou-se nos temas propostos pelos integrantes nas rodas de conversas ou surgidos durante os trabalhos corporais. A qualidade estética da produção dos participantes resultou em satisfação pessoal e grupal e provocou admiração do público que visitou o ateliê e a exposição organizada a partir dessa produção.
\end{abstract}

Palavras-chave: Terapia Ocupacional, Arte, Cultura, Idoso.

\section{Producing access for the elderly to territories of culture: an experience of occupational therapy in an art museum}

\begin{abstract}
From 1996 to 2009, the Laboratory for Studies and Research in Art, Body and Occupational Therapy established a cooperation with the Museum of Contemporary Art of USP (MAC USP), working in partnership with the Leisure and Art to the Elderly Program of the Education and Technical-Scientific Division of MAC USP. The program offers an introduction in contemporary artistic practice to the elderly. This paper presents the interdisciplinary experience developed in this partnership in 2006. The method adopted in the program is referenced in the Triangular Approach to Teaching Art. Therefore, the appreciation of works of art and the contextualization of selected artists formed the basis on which participants developed their own poetics. The preparatory work was developed in group
\end{abstract}

Autor para correspondência: Ana Tereza Costa Galvanese, Departamento de Medicina Preventiva, Faculdade de Medicina, Universidade de São Paulo, Av. Dr. Arnaldo, 455, $2^{\circ}$ andar, 01246-000, São Paulo, SP, Brasil, e-mail: anagalvanese@usp.br

Recebido em 28/9/2011; Revisão em 20/8/2012; Aceito em 7/11/2012. 
dynamics, including activities of body awareness and conversation circles coordinated by occupational therapists and students. They also accompanied the participants in their demands related to the challenges of constructing access to socio-cultural territories. The relevance of this living process was evident in the topics proposed by participants in conversations, or arisen during the body work. The aesthetic quality of the participants' production resulted in personal and collective satisfaction and provoked admiration of the public who visited the workshop and exhibition, organized from this production.

Keywords: Occupational Therapy, Art, Culture, Elderly.

\section{Introdução}

O entendimento da saúde como produção de vida desdobra-se, na atualidade, em propostas de atenção comprometidas com a transformação de espaços sociais e culturais, a fim de que uma multiplicidade de modos de existir possam se fazer neles presentes e constituí-los. Com esse foco, experiências de atividades artísticas com potencial de participação social e convivência com a alteridade têm motivado terapeutas ocupacionais e outros atores sociais envolvidos nesse processo a refletirem sobre a qualidade do acesso de sujeitos e grupos diversos aos serviços e eventos artísticos e culturais.

O Laboratório de Estudos e Pesquisa Arte e Corpo em Terapia Ocupacional, do Curso de Terapia Ocupacional da Faculdade de Medicina da USP, tem pesquisado novas metodologias de intervenção na interface das artes e da produção da saúde através de seu projeto didático-assistencial Programa de Composições Artísticas e Terapia Ocupacional (PACTO), potencializando a formação de alunos na graduação em Terapia Ocupacional e de outros profissionais das artes, da saúde e da educação.

É nessa perspectiva que se insere a participação de terapeutas ocupacionais no Programa Lazer com Arte para a Terceira Idade (LAPTI), uma das ações desenvolvidas pelo acordo de cooperação entre o Laboratório de Estudos e Pesquisa Arte e Corpo em Terapia Ocupacional e a Divisão Técnico-Científica de Educação e Arte do Museu de Arte Contemporânea da USP (MAC-USP) (COUTINHO et al., 2009). O LAPTI oferece à comunidade idosa um ateliê semanal coordenado pelo arte-educador Sylvio Coutinho, que contou, durante 12 anos, com a participaçáo de estagiários do quarto ano de graduação em Terapia Ocupacional, supervisionados por terapeutas ocupacionais, além dos assistentes do ateliê.

Neste artigo apresentaremos a experiência de colaboração entre a Terapia Ocupacional e o LAPTI, desenvolvida durante 2006, buscando mapear, nessa experiência, as principais linhas que sustentaram a reflexão e caracterizaram as açóes dos terapeutas ocupacionais aí desenvolvidas.

\section{Cultura, subjetividade e linhas de exclusão na contemporaneidade}

$\mathrm{O}$ acesso às redes de sentido e de existência que, há poucas décadas atrás, se dava por relaçóes de comunidade e seus critérios intrínsecos, deslocou-se do âmbito social e passou a ser mediado por pedágios comerciais, condenando um grande contingente de pessoas a um estranho sedentarismo, à lerdeza, à imobilidade. Excluídos do fluxo, das conexóes, do acesso aos espaços de produção e de informação, esses sujeitos ficam prisioneiros de suas condiçôes de vida, marcada pela luta pela sobrevivência cotidiana e pela impossibilidade de criar laço social (PÉLBART, 2003).

Nesse contexto, grupos humanos implodem, perdem suas referências, veem suas identidades se desagregarem; linhas de exclusão social se combinam à vulnerabilidade relacional, à precariedade $\mathrm{da}$ sobrevivência material, à privação da experiência cultural, ao desenraizamento étnico, estético ou ético.

Tomando por referência o entendimento da cultura como processo contínuo de ação humana no mundo, no qual grupos humanos produzem histórias e signos em seu tempo e lugar, procuramos focalizar algumas dimensóes constitutivas da subjetividade e certas configurações do sofrimento psíquico e da exclusão social na contemporaneidade que constituem problemáticas a serem enfrentadas pelos terapeutas ocupacionais.

Para o enfrentamento dessas problemáticas interessam algumas abordagens do âmbito da psicanálise que tecem consideraçóes relevantes e buscam mapear pontos de emergência da experiência cultural e de inscrição social dos sujeitos. Para Safra (1999), desde o início da vida o ser humano demanda a presença, o gesto e a subjetividade do outro. Para esse autor, o enraizamento cultural e a 
experiência estética iniciam-se, na vida humana, pela codificação que se estabelece sensorialmente entre o bebê e o mundo.

$\mathrm{Na}$ medida em que o bebê toma o corpo materno como o próprio corpo, organiza-se segundo os aspectos étnicos da comunidade em que nasceu (SAFRA, 2002, p. 36).

Essa matriz étnica é incorporada pela criança no convívio social e se manifesta no seu modo de ser: sua apropriação do ethos, sua organização estética, corporeidade, emoçôes, sentimentos e atitudes. Dessa forma, o enraizamento cultural tem dimensões étnicas, éticas e estéticas.

Contudo, para que a experiência cultural se estabeleça é necessária a constituição de um espaço potencial entre a realidade psíquica do indivíduo e o seu ambiente (WINNICOTT, 1975). A criança vivencia o espaço potencial na brincadeira, construindo um sentimento de confiança no ambiente através da experimentação. Esse processo é vital para a fruição da criatividade; por outro lado, privaçôes dessa experimentação dificultam sua expressão. Em qualquer tempo da vida, contudo, a experiência cultural pode ser vivida num espaço entre a realidade pessoal e aquela compartilhada através de oportunidades que a favoreçam.

Criatividade e cultura combinam-se, em contínuo processo de integração e ação recíproca entre a originalidade e a aceitação da tradição, oferecendo a base da inventividade (WINNICOTT, 1975).

Há, então, uma dimensão da subjetividade que se desenvolve para além do indivíduo:

[...] cada grupo social veicula seu próprio sistema de modelizaçáo da subjetividade, quer dizer, certa cartografia feita de demarcaçôes cognitivas, mas também míticas, rituais, sintomatológicas, a partir do qual ele [o indivíduo] se posiciona em relação aos seus afetos, suas angústias e tenta gerir suas inibiçóes e suas pulsóes (GUATTARI, 1992, p. 22).

Esse sistema de modelização assume configurações crescentemente complexas na contemporaneidade, com o surgimento de um novo modo de relação entre o capital e a subjetividade. $\mathrm{O}$ atual funcionamento do capitalismo, em rede, captura o desejo com impressionante eficiência, produzindo configuraçôes sociais nas quais os valores culturais são cada vez mais produtos de consumo:

[...]consumimos, mais do que bens, formas de vida [...] através dos fluxos de imagem, de informação, de conhecimento e de serviços que acessamos constantemente, absorvemos maneiras de viver, sentidos de vida, consumimos toneladas de subjetividade (PÉLBART, 2003, p. 20).

Nesse contexto, modelos de subjetivação induzem ao esquecimento de si, à perda de referências e à experiência de desenraizamento (SAFRA, 2002). As transformaçóes contínuas e rápidas de paisagens científicas, técnicas, econômicas, profissionais, mentais, os avanços da biologia e da medicina estabelecem a vivência de uma temporalidade acelerada, fazendo surgir organizaçôes estéticas em um ritmo desconectado dos ritmos e sentidos da corporeidade humana.

Esse quadro nos motiva a refletir sobre questôes fundamentais da existência humana e a procurar caminhos para a produçáo de sentido. As novas técnicas de informação, paradoxalmente, instauram novas formas de comunicação, de troca e de relação entre humanos e entre o homem e a tecnologia. O problema do laço social é colocado em novas bases, trazendo a possibilidade de pensar coletivamente e compartilhar conhecimentos através de novas conexôes entre inteligência, experiência, saberes, imaginação, práticas, o que possibilita pensar em conjunto e incrementar o campo da invençáo.

\section{Arte como poder e como potência: composições}

Enfrentar e combater o adoecimento contemporâneo que, para Guattari (2004), atravessa todas as esferas da vida - subjetiva, relacional e ambiental -, pede a reinvenção da relação com o corpo, com a doença, com a morte e a construçáo ou renovação do laço social. É necessário valorizar e possibilitar a formaçáo de redes de sociabilidade nas quais possam ser inventadas e validadas modalidades singulares de agregar-se, de criar sentido, de trocar experiências, de cooperar, de experimentar o corpo, de organizar o cotidiano, de relacionar-se com a alteridade e de lidar com os sofrimentos.

Alguns dispositivos que promovem composiçôes entre arte e clínica participam desse enfrentamento ao possibilitarem o encontro entre uma dimensáo clínica da arte e uma dimensão estética da clínica, espécie de revitalização que Rolnik (1996) denominou de "estado de arte" na subjetividade. Um estado no qual está em açáo a potência de um corpo ser afetado pelos encontros com outros corpos e de criar, a partir desses encontros e dessas afetações, novos corpos, novos objetos, novas formas de vida. A singularidade da clínica reside em dar suporte às experiências desencadeadas nessa mobilização 
e trabalhar seus impedimentos, apostando que a invençáo é potência de todos e de cada um.

Para a Terapia Ocupacional, a produção desse suporte demanda a criação de atividades com função intercessora, ou seja, com potencial de intensificação das sensibilidades, de abertura a percepçôes, imaginaçôes e memórias; com força para despertar a heterogênese (DELEUZE, 1992). Afirmar a disposição para composiçôes restauradoras do "estado de arte" em espaços culturais pode demandar de nós, terapeutas ocupacionais, um olhar e uma escuta atentos aos pontos de força que podem ser intensificados pelo convite à experiência, por meio do incremento que a proposição de algumas atividades pode empreender.

É quase certo, contudo, que nos deparemos também com organizaçóes estéticas padronizadas que, marcadas pelo conceito de arte como objeto de consumo, tendem a dificultar a experiência de um "estado de arte". Ancorados nessa suposiçáo, procuramos focalizar um dinamismo de forças presente no indivíduo e atuante no contínuo criar e transformar a vida: forças que se manifestam, mesmo que momentaneamente, em oposiçóes criativas.

Muitas pesquisas de intervenção, no campo da clínica, da educação e das artes ocorrem no sentido de encontrar modos de operar essa revitalizaçáo. A experiência da parceria entre o PACTO e o LAPTI - responsáveis pela sustentação grupal e pela orientação artística, respectivamente - será aqui tomada como exemplar de uma dessas pesquisas, no recorte de uma intervenção que aconteceu no decorrer de um ano, com encontros semanais de quatro horas, matinais, nos meses de março a dezembro.

\section{$4 \mathrm{O}$ ateliê do LAPTI no ano de 2006}

Com o objetivo de facilitar o acesso do público de terceira idade à arte moderna e contemporânea, o LAPTI desenvolve atividades plásticas em ateliê, participação em palestras sobre os temas abordados, visitas às exposiçóes do acervo do Museu e a outras exposiçóes da cidade, entre outras atividades.

Todas essas atividades são desenvolvidas na perspectiva da Abordagem Triangular, com suas açôes básicas de apreciar, contextualizar e fazer (BARBOSA, 2008).

Durante o ano de 2006, a escolha para a programação das atividades do LAPTI recaiu sobre uma obra contemporânea que passara a integrar o acervo do Museu: o grande painel The Foundling, do artista plástico norte-americano
Frank Stella, que ocupava sozinha - pelas suas dimensôes monumentais - uma galeria inteira do espaço expositivo. O impacto da novidade implicada nessa obra, os desdobramentos de suas complexas leituras e interpretaçôes, apontaram para um amplo percurso de estudos e experimentações em ateliê.

As investigaçóes em torno da obra - cuja composição retoma as volutas imbricadas da fumaça do charuto do artista, fotografadas e tratadas graficamente por meio digital - mobilizavam desde a apreciação dos fenômenos físicos desencadeadores, estudados pela Teoria do Caos e reivindicados na gênese mesma dessa obra, até suas ligaçôes com a cultura literária do autor. Sem esquecer seus enraizamentos na história da arte abstrata, desde os primórdios da tradição celta, passando pelos arabescos e formulaçóes geométricas avançadas da cultura oriental, atingindo dimensôes da alta abstração do decorativismo em Matisse. O estudo da obra desdobrou-se também em incursões a poéticas de artistas brasileiros como Nuno Ramos - que já expôs junto com Frank Stella -, Ligia Pape - a quem a "pintura negra" da fase minimalista de Stella parece tanto dever - e à pintura corporal do índio brasileiro.

Finalizamos a programação do ano aproveitando os signos presentes no painel de Stella que citam e remetem à poética de Roy Lichtenstein, com suas explosóes de retículas de modalidade figurativa, e na qual também despontam as marcas poéticas de Andy Warhol, Robert Rauschenberg, Claudio Tozzi e Rubens Gerchman. Todos esses artistas foram, assim, incorporados aos nossos estudos. A digitalidade, presente nos procedimentos de Stella, também marcou, em nosso ateliê, muitos dos procedimentos implicados na criação das obras dos participantes do LAPTI.

\section{Linhas constitutivas do trabalho de Terapia Ocupacional em 2006}

A presença da Terapia Ocupacional caracterizou-se pelo contínuo convite à vivência dos ateliês enquanto espaços de aprendizagem em arte e buscou potencializar as trocas sociais, os espaços de criação e a experimentação de um "estado de arte".

O terapeuta ocupacional e o estagiário participaram de todos os momentos da proposta. Suas principais atribuições foram a condução da dinâmica de grupo, que abria cada encontro, e os acompanhamentos individuais durante o desenvolvimento dos ateliês. 
As dinâmicas de grupo foram compostas de vivências de integração psicofísica; consciência e expressão corporal; e rodas de conversa, nas quais os integrantes propunham temas novos ou retomavam temas surgidos nas práticas integrativas, nas vivências de ateliê ou sugeridos pelos terapeutas a partir de suas observaçôes. Entre os temas mais frequentes estavam: as percepçôes, crenças, polêmicas e relatos sobre saúde e envelhecimento; a forma como os integrantes experimentavam a proposta do ateliê e as dificuldades que se apresentavam na execução dos trabalhos; as percepçóes sobre o cotidiano capturado pela realização constante de tarefas, a falta de tempo para a observação do próprio corpo, do entorno e de como esses se relacionavam; e percepçóes do corpo trabalhado.

Já os acompanhamentos individuais aconteciam, eventualmente, durante a realização do ateliê, quando algum participante solicitava a atenção do terapeuta.

Com base nessa experiência, algumas configuraçóes do trabalho do terapeuta ocupacional nesse espaço se revelaram:

- No acompanhamento aos participantes, em suas demandas ligadas aos desafios da criação, da experiência estética e da participaçáo social;

- No suporte, quando necessário, à presença e continuidade dos participantes nas atividades do ateliê;

- Na promoção de momentos de convivência, compartilhamento de experiências e cuidado mútuo;

- No compartilhamento de recursos para a vivência da corporeidade no fazer artístico.

Tais contornos, que emergiram dessa práxis, nos convidam a indagar a ética das relaçôes, já que relaçôes de composiçấo, diferentemente daquelas regidas pela dominação:

[...] não são nem adequaçôes harmoniosas entre diferenças, nem fusões totalitárias fadadas a tornarem todos os seres similares. Trata-se de estabelecer uma composição na qual os seres envolvidos se mantêm singulares, diferentes, do começo ao fim da relação: a composição entre eles realça tais diferenças sem, contudo, degradar qualquer uma delas em proveito de outras (SANT'ANNA, 2001, p. 95).

Tendo esta ideia de composição como eixo norteador do trabalho, destacamos a seguir algumas direçôes que podem ser exploradas no trabalho de Terapia Ocupacional em espaços culturais.

\subsection{A escuta e o conversar}

A necessidade de uma escuta atenta era nítida no grupo, apresentando-se como uma demanda claramente colocada por cada sujeito ao terapeuta e aos outros participantes. Maturana apud Ruiz (1999, p. 68) afirma que a experiência humana se processa através do "conversar, num entrelaçamento entre o linguajar e o se emocionar", considerando a cultura como "uma rede fechada de conversaçóes e que as mudanças culturais acontecem quando se produzem modificaçôes nessas conversas".

Mas, se o conversar com o outro é próprio da experiência cultural, o processo de envelhecimento parece contribuir para torná-lo mais evidente como necessidade humana. No grupo que frequentava o LAPTI, no ano de 2006, tal necessidade revelou-se na demanda por compartilhar - e nessa medida transformar - situações de sofrimento experimentadas no corpo, nas convivências e nas relaçóes com o entorno.

\subsection{Holding}

Situaçóes em que se apresentavam demandas de holding eram frequentes durante o ateliê, em momentos de desafio estético ou técnico; e muitas vezes configuravam-se no pedido de que o terapeuta ou estagiário ficasse ao lado do participante, acompanhando e dando sustentação para sua experimentação.

Segundo o psicanalista Barretto (1998), holding, ou sustentação, da mesma forma como definido por Winnicott, é

[...] tudo que, no ambiente, fornecerá a uma pessoa a experiência de uma continuidade, de uma constância tanto física quanto psíquica[...] (BARRETTO, 1998, p. 60).

Em outras palavras: holding refere-se à função de dar suporte às experiências do sujeito, através da construção vincular, no momento imediato em que elas acontecem. No ateliê, muitas vezes, ficar ao lado de algum participante era suficiente para reinstaurar uma autoconfiança momentaneamente abalada, ou mesmo favorecer seu aparecimento.

\subsection{Continência}

As situaçóes em que a continência mostrava-se importante eram aquelas em que havia a necessidade de construir um contorno à experiência do sujeito, para que ele pudesse transformá-la, através da imaginação, fazendo-a ganhar sentido e consistência. 
A continência é um suporte muitas vezes necessário para que acontecimentos no campo social possam efetivar-se e serem elaborados, transformando-se em experiência (BARRETTO, 1998).

No ateliê, a demanda por continência evidenciava-se particularmente em situaçôes de enfrentamento do novo. A ampliação do repertório de linguagens era uma aquisição provavelmente desejada por aqueles que procuravam o ateliê. Ao mesmo tempo, essa aquisição implicava empenho e disponibilidade para diálogos e confrontaçóes entre modos de ver: seja em relação à arte, seja em relação à vida ou a si mesmo. Tais diálogos se davam ora em afinação, ora em dissonância, gerando transformaçóes. Sustentá-las dependia do sujeito e do ambiente, mas também do suporte oferecido.

Assim como a escuta, o holding e a continência não são demandas específicas das pessoas idosas: são demandas que se manifestam, com frequência, no desenrolar de processos criativos e em processos de participação social, em que o sujeito ousa percursos, na transição do meramente estar no social para o “ser no social” (MARQUES, 1991, p. 205).

\subsection{Corporeidade}

A dança, a pesquisa de movimento e as vivências de integração psicofísica compunham as dinâmicas de grupo e propiciavam momentos de conexão na preparaçáo dos corpos para a entrada no processo criativo.

Segundo Favre (2005, p. 3), “corpos são essencialmente conectores: canais de conexôes físicas, ambientais, de afetos e de saberes". Através das suas expressóes, o corpo pode conectar-se a redes e coletivos; pode pulsar como corpo vivo; pode ser mais ou menos permeável aos ambientes, nutrir-se de afetos, de imagens, de informaçóes. Mas pode também acontecer o isolamento e o corpo tornar-se refratário, desvitalizado e só.

O trabalho com a dança visava contribuir para a reversão do isolamento, ao criar, no encontro com o outro, a possibilidade do gesto. Através da dança,

comunicamo-nos com o nosso corpo, estimulados pelo desejo de expressar-nos com a música ou sem ela, mas fazendo do corpo um instrumento de comunicação entre o que queremos fazer, o que podemos fazer e entre o que vamos descarregando para podermos nos expressar (FUX, 1983, p. 67).

No contexto do ateliê, a vivência da corporeidade pareceu contribuir para o acolhimento das intensidades vividas no corpo e para sua sustentaçáo e expressão, na busca da experimentação de um "estado de arte".

\subsection{Trocas sociais}

O contexto do desenvolvimento do ateliê - o fato de se estar em um museu de arte - assim como a motivação artística e cultural que aglutinou o grupo orientaram os desdobramentos e os modos de expansão das relaçóes dos participantes para além do ateliê em si: tanto através de programaçóes culturais auto-organizadas, que incluíram outras pessoas de suas redes de relaçóes, quanto na exposição organizada no MAC-USP a título de finalização anual das atividades do LAPTI.

Naquela exposição, a qualidade estética dos trabalhos apresentados foi elogiada em divulgaçóes pela imprensa local e em registros no livro de presença, escritos por frequentadores habituais do museu e pelo público em geral. Desse modo, o retorno aos participantes se deu em forma de reconhecimento do valor da sua arte.

As oportunidades de ampliação das redes de sentido e existência, para esses últimos, tiveram como base suas próprias referências culturais, atualizadas pelo acesso a novas referências e pelo processo de criar e compartilhar suas produçôes. Desse modo, os sentidos apropriados pelos participantes através da experiência cultural puderam dar sustentação a novos diálogos e trocas sociais.

\section{Considerações finais}

Com a intençáo de delinear alguns eixos para o trabalho na interface entre as artes e a saúde, procuramos compartilhar essa experiência. Através dela pudemos observar que entre o aprendizado das técnicas e a expressão própria instaura-se, ainda que momentaneamente, um campo de tensão em que maneiras distintas de estar nos ambientes e na vida podem produzir composiçóes éticas das quais as diferenças podem participar, fazendo emergir novas relações.

Seja qual for sua matéria de expressão, a experimentação de um "estado de arte" envolve múltiplas dimensões do ser, com facetas e desdobramentos insondáveis, que eventualmente necessitam de algum acolhimento para florescerem como criação.

No trabalho no ateliê do LAPTI o interesse se manifestou na pesquisa de planos de composição passíveis de criarem mundos e ganharem consistência, na manipulação de matérias de expressão. 
Estabeleceu-se, assim, uma forte conexão entre a experiência da criação, a produção de saúde e a potencialização da vida.

Esperamos que essa experiência, assim como muitas outras que envolvem a participaçáo da Terapia Ocupacional no trânsito com os campos das artes e da cultura, possa contribuir para um debate fértil e enriquecedor no interior da profissão e nas suas interfaces para que, para todos, e cada vez mais, saúde possa significar vida criativa e presença no mundo.

\section{Referências}

BARBOSA, A. M. (Org.). Ensino da Arte: memória e história. São Paulo: Perspectiva, 2008.

BARRETTO, K. D. Ética e Técnica no Acompanhamento Terapêutico. São Paulo: Unimarco, 1998.

COUTINHO, S. et al. A. Açóes de Terapia Ocupacional no Território da Cultura: uma experiência de cooperaçáo entre o MAC USP e o Laboratório de Estudos e Pesquisa Arte e Corpo em Terapia Ocupacional. Revista de Terapia Ocupacional da USP, São Paulo, v. 20, n. 3, p. 188-192, 2009. http://dx.doi.org/10.11606/issn.2238-6149. v20i3p188-192

DELEUZE, G. Conversaçōes. São Paulo: Editora 34, 1992.

FAVRE, R. A Construção Somática como um modo de Invenção da Vida. São Paulo: [s.n.], 2005. Transcrição de palestra ministrada no $2^{\circ}$ Encontro da série: Subjetividade e Contemporaneidade.
FUX, M. Dança, experiência de vida. São Paulo: Summus, 1983.

GUATTARI, F. As três ecologias. 15. ed. Tradução de Maria Cristina F. Bittencourt. Campinas: Papirus, 2004.

GUATTARI, F. Caosmose: um novo paradigma estético. Săo Paulo: Editora 34, 1992.

MARQUES, M. R. M. Atelier Bricoleur: intervenção no atendimento das psicoses. Revista de Terapia Ocupacional da USP, São Paulo, v. 2, n. 4, p. 201-210, 1991.

PÉLBART, P. P. Vida Capital: ensaios de biopolítica. São Paulo: Iluminuras, 2003.

ROLNIK, S. Lygia Clark e o híbrido arte/ clínica. Percurso: Revista de Psicanálise, São Paulo, v. 8, n. 16, p. 43-48, 1996.

RUIZ, A. Humberto Maturana e a Psicoterapia. Revista Thot, São Paulo, v. 70, p. 61-69, fev. 1999.

SAFRA, G. A Face Estética do Self: teoria e clínica. São Paulo: Unimarco, 1999.

SAFRA, G. Desenraizamento e exclusão no mundo contemporâneo. In: VAISBERG, T. A.; AMBROSIO, F. F. Trajetos do Sofrimento: Desenraizamento e Exclusão. São Paulo: Instituto de Psicologia, Universidade de São Paulo, 2002. p. 34-40.

SANT'ANNA, D. B. Corpos de Passagem: ensaios sobre a subjetividade contemporânea. São Paulo: Estação Liberdade, 2001.

WINNICOTT, D. W. A Localização da Experiência Cultural. In: WINNICOTT, D. W. O Brincar e a Realidade. Rio de Janeiro: Imago, 1975. p. 152-164.

\section{Contribuições dos Autores}

Ana Tereza Costa Galvanese colaborou na produção e análise das informaçôes, na concepção e redação do artigo; Sylvio Coutinho, na produção das informações e redação do artigo; Erika Alvarez Inforsato, na redação e revisão do artigo; e Elizabeth Maria Freire de Araújo Lima, na análise das informaçóes, na concepção, redação e revisão final do artigo. 